\title{
THE COMPETITIVE ACTIVITY STRUCTURE OF HIGHLY SKILLED BASKETBALL PLAYERS ON THE BASIS OF FACTOR ANALYSIS METHODS
}

original paper

( ) University School of Physical Education in Wroclaw

DOI: https://doi.org/10.5114/hm.2019.85091

\section{EDWARD DOROSHENKO ${ }^{1}$, RUSLANA SUSHKO ${ }^{2}$, VICTOR KORYAHIN ${ }^{3}$, MARYAN PITYN ${ }^{4}$, IAROSLAV TKALICH ${ }^{1}$, OKSANA BLAVT ${ }^{3}$}

${ }^{1}$ Zaporizhzhia State Medical University, Zaporizhzhia, Ukraine

${ }^{2}$ Borys Grinchenko Kyiv University, Kyiv, Ukraine

${ }^{3}$ Lviv Polytechnic National University, Lviv, Ukraine

${ }^{4}$ Lviv State University of Physical Culture, Lviv, Ukraine

\section{ABSTRACT}

Purpose. To analyse and generalize the competitive activity structure on the basis of the hierarchy of technical and tactical indicators of qualified basketball players in won and lost games by using the factor analysis methods.

Methods. The study involved 96 professional basketball players who were national team players of countries that took 1-8 places in the final tournament of the European Basketball Championship 2017. Technical and tactical indicators of their competitive activity were analysed for revealing and interpreting the results with the factor analysis methods.

Results. The grouping of elements of the competitive activity structure of highly skilled basketball players was analysed. Groups with the highest value of factor capacity depending on the results of the game were determined. A significant difference in the structure of technical and tactical activity in the won and lost games was presented.

Conclusions. The data obtained in the course of the study on the basis of factor analysis allowed us to present updated information on the competitive activity structure of highly skilled basketball players and to partially confirm the existing data. Key words: basketball, structure, technical and tactical activity, methods of factor analysis

\section{Introduction}

The general theory of sport and modern athletes training systems consider the cycle of the most important problems for the further improvement of the training process. Most authoritative researchers in the field of physical education and sports agree that the issues of improving the training process and competitive activities are of highest importance. One of the topical problems is the study of the competitive activities structure in a specific kind of sport with the application of complex nonlinear methods of mathematical processing of the studied indicators [1]. The methods allow to integrate the knowledge of mathematical sciences for the further development of the general theory of sport and improving the athletes training system in a specific kind of sport [2-4]. Such approaches are not completely new, but have high practical and theoretical signifi- cance and involve a number of problems that do not have a final conclusion, as well as common points of view among both scientists and practitioners in the field of team sports games that are very popular and have a spectator interest. Significant scientific studies in this area include the work of Kozina [5], Kozina et al. [6], Okazaki and Rodacki [7], Kabaciński et al. [8]. These studies, using the material of team sports games (volleyball, handball) and applying factor analysis methods, investigated the athletes' physical preparedness structure and determined the factor models of game activity. One of the first studies of the competitive activity structure in qualified athletes in basketball with the use of factor analysis methods is the research by Kyrychenko and Doroshenko [9], performed on the basis of the indicators of the competitive activity of qualified basketball players who participated in European cup tournaments in 2003 and 2005. These

Correspondence address: Oksana Blavt, Department of Physical Education, Lviv Polytechnic National University, 12 Bandera Str., Lviv, 79013, Ukraine, e-mail: oksanablavt@ukr.net

Received: October 18, 2018

Accepted for publication: April 3, 2019

Citation: Doroshenko E, Sushko R, Koryahin V, Pityn M, Tkalich J, Blavt O. The competitive activity structure of highly skilled basketball players on the basis of factor analysis methods. Hum Mov. 2019;20(4):33-40; doi: https://doi.org/10.5114/hm.2019.85091. 
E. Doroshenko et al., Competitive activity structure in basketball

authors attempted to use the method of principal components with the Kaiser normalization and varimax orthogonal rotation of the matrix to study the competitive activity structure.

In modern sports science, the issues connected with the use of factor analysis methods for studying the various aspects of preparedness and competitive activity of highly skilled basketball players remain relevant. Non-linear methods of multidimensional mathematical analysis were applied in studies of competitive activity indicators in the Spanish professional basketball league [10], at the final tournament of the European Championship 2015 [11], in elite women basketball teams while preparing for youth Olympic tournaments [12].

The problems with using factor analysis methods to reveal the consistent patterns of team, group, and individual dynamics of the competitive activity effectiveness in basketball were described in the studies by Bazanov et al. [13], Kozina et al. [14], Villa and Lozano [15]. An analysis of factor variables that determine the parameters of teamwork of qualified basketball players in conditions of increasing competitive activity is presented in a study by Gruber and Gray [16]. A similar methodological principle was employed by Kozina et al. [14], who made an attempt to determine the individual characteristics of the complex athletes' preparedness with the help of mathematical modelling and multivariate statistical analysis methods. Hopkins [17] and Koryahin et al. [18] proposed an algorithm for selecting the most optimal test tasks for determining the level of various aspects of preparedness of qualified basketball players [8] with the use of multidimensional statistical analysis methods, which is based on the hierarchy of both indicators of athletic preparedness and their significance from the point of view of test theory. A similar study was conducted by Karpowicz and Karpowicz [19] among young Polish basketball players aged 15-16 years observed for a long time.

Further development of research approaches based on the use of multidimensional mathematical analysis methods in the system of training qualified basketball players can be observed in studies by Sampaio et al. [20] or Sporiš et al. [21]. Also, Scanlan et al. [22], on the basis of the comparative characteristics of the requirements to actions of highly skilled basketball players of Australian basketball leagues, showed the possibilities of studying the hidden structure of standard indicators of game efficiency in basketball. Research has used the multivariate statistical analysis methods to determine the technical and physical preparation of highly qualified basketball players, as well as the level of development of their aerobic and anaerobic functions [18]. Discriminant analysis of highly skilled basketball players' game efficiency is shown as an adequate method of research in the field of competitive activity.

The methods of factor analysis are suitable in the study of theoretical [23] and practical [24] problems of qualified basketball players training system. In the presented study, an attempt was made to investigate the indicators of the competitive activity structure in qualified basketball players on the materials of the European Basketball Championship 2017 by using the methods of factor analysis.

The study of the technical and tactical activity of qualified basketball players and the results interpretation with the help of the factor analysis methods will make possible the understanding of modern trends in the development of modern basketball.

It was hypothesized that the grouping of the competitive activity structure elements of qualified basketball players with the factor analysis methods presented significant differences in technical and tactical indicators in won and lost games. Therefore, it requires studying in order to increase efficiency through professional correction of the training process.

The purpose of the study was to analyse and generalize the competitive activity structure on the basis of the technical and tactical indicators hierarchy in qualified basketball players in won and lost games by using the factor analysis methods.

\section{Material and methods}

\section{Participants}

The study involved 96 professional basketball players who were national team players of 8 countries (Slovenia, Serbia, Spain, Russia, Latvia, Germany, Italy, Greece) that took 1-8 places in the final tournament of the European Basketball Championship 2017. Factor analysis methods were applied to study the competitive activity structure indicators in order to determine their hierarchy and interpret the obtained results depending of the differences in the won and lost games. In the process of factor analysis, we used 11024 indicators of competitive activity of qualified basketball players in 64 games: 7936 indicators in 46 won games and 3088 indicators in 18 lost games.

\section{Procedure}

Between August 31 and September 17, 2017, the final tournament of European Basketball Championship 
Table 1. Final results of the top 8 teams in the final tournament of the European Basketball Championship 2017

\begin{tabular}{cccccc}
\hline Place & Team & $\begin{array}{c}\text { Number } \\
\text { of games }\end{array}$ & Won & Lost & Ratio \\
\hline 1 & Slovenia & 9 & 9 & - & - \\
2 & Serbia & 9 & 7 & 2 & 3.5 \\
3 & Spain & 9 & 8 & 1 & 8 \\
4 & Russia & 9 & 6 & 3 & 2 \\
5 & Latvia & 7 & 5 & 2 & 2.5 \\
6 & Germany & 7 & 4 & 3 & 1.33 \\
7 & Italy & 7 & 4 & 3 & 1.33 \\
8 & Greece & 7 & 3 & 4 & 0.75 \\
Total & & 64 & 46 & 18 & 2.56 \\
\hline
\end{tabular}

2017 was held in 4 countries (Finland, Israel, Romania, Turkey). It was attended by 24 national teams. The results of the performance of the top 8 teams (the total number of games, the number of wins and losses) are presented in Table 1.

\section{Statistical analysis}

With the use of the factor analysis methods, the elements of the structure of competitive activity were grouped according to individual indicators of qualified basketball players. To process the results, the specialists of the Department of Physical Rehabilitation, Sports Medicine, Physical Education and Health of the Zaporizhzhia State Medical University used the SPSS-12 computer software. To study the competitive activity structure of qualified basketball players at the final tournament games of the European Basketball Championship 2017, the principal component analysis with Kaiser normalization and varimax orthogonal rotation of the primary $\mathrm{R}$ matrix were applied. The principal component analysis differs from other factor analysis methods in that the diagonal elements of the primary $\mathrm{R}$ matrix used in the component analysis equal one (i.e. 1 or -1) in each case [9]. The differences between factor analysis and component analysis are related to the specificity of problems that are solved with the help of these methods of analysis.

\section{Ethical approval}

The research related to human use has complied with all the relevant national regulations and institutional policies, has followed the tenets of the Declaration of Helsinki, and has been approved by the Human Ethics committee of the University of León, León, Spain.

\section{Informed consent}

Informed consent has been obtained from all individuals included in this study.

\section{Results}

Tables 2-4 show the grouping of indicators that form the competitive activity structure of qualified basketball players. The competitive activity structure of qualified basketball players in the games of the final tournament of European Basketball Championship 2017 (Table 2, number of games: 64) was studied by the factor analysis methods with respect to the specifics of the tasks that were being solved in this study.

To determine the specifics of the competitive activity structure of qualified basketball players in won and lost games by using the factor analysis, the corresponding athletes' indicators were analysed (Table 3 , number of games won: 46; Table 4, number of games lost: 18).

According to an American study [25], a significant degree of reliability of the obtained indicators characterizing the competitive activity structure is achieved if the percentage of sampling its elements is at least $60 \%$. As applied to this research, in order to group elements of the overall competitive activity structure of the qualified basketball players in accordance with the most significant indicators of factor loading, the percentage of the sample elements that are significantly interrelated (correlated) is $67.59 \%$ (Table 2). The value equals $67.42 \%$ for the won games (Table 3 ) and $69.5 \%$ for the lost games (Table 4). The obtained data indicate a sufficiently high degree of reliability of the results.

Also significant is the distribution of indicators in the factor groups by the absolute value: values $>0.7$ indicate the presence of statistically significant differences; those between $>0.5$ and $<0.7$ indicate a trend towards statistically significant differences.

It is worth to notice the coincidence of groups of elements in the overall structure and the structure of competitive activity in the won matches. At the same time, there are significant differences between these 2 groups and the structure of competitive activity in highly skilled basketball players in the matches played.

In the won games, the first group of factors includes offensive rebounds, defensive rebounds, and, as a result, the total number of rebounds. In the lost games, the first group of factors involves quantitative and qualitative indicators of 3-point shots and scored points.

The second group of factors comprises quantitative and qualitative indicators of 3-point shots in the 


\section{HUMAN MOVEMENT}

E. Doroshenko et al., Competitive activity structure in basketball

Table 2. Grouping of competitive activity general structure elements in qualified basketball players in accordance with the factor loading values, $n=11024$

\begin{tabular}{lcccc}
\hline \multirow{2}{*}{$\begin{array}{l}\text { Indicators } \\
\text { of competitive activity }\end{array}$} & \multicolumn{4}{c}{ Values of factor loading } \\
\cline { 2 - 5 } & Group 1 of factors & Group 2 of factors & Group 3 of factors & Group 4 of factors \\
\hline Time (min) & 0.444 & $0.573^{*}$ & 0.353 & 0.383 \\
2-point shots $(n)$ & 0.325 & 0.069 & $0.663^{*}$ & 0.436 \\
2-point shots (\%) & 0.383 & 0.086 & $0.639^{*}$ & 0.432 \\
3-point shots $(n)$ & 0.009 & 0.859 & 0.182 & -0.052 \\
3-point shots (\%) & 0.045 & 0.878 & 0.224 & 0.044 \\
Free throws $(n)$ & 0.110 & 0.172 & 0.894 & -0.034 \\
Free throws (\%) & 0.176 & 0.143 & 0.894 & -0.0123 \\
Offensive rebound $(n)$ & 0.699 & -0.245 & 0.144 & 0.082 \\
Defensive rebound $(n)$ & 0.799 & 0.241 & 0.220 & 0.061 \\
Total rebounds $(n)$ & 0.929 & 0.0995 & 0.221 & 0.059 \\
Assists $(n)$ & 0.0568 & 0.5839 & 0.129 & 0.365 \\
Fouls $(n)$ & 0.0865 & -0.061 & -0.006 & $0.646^{*}$ \\
Turnovers $(n)$ & 0.034 & 0.209 & 0.265 & $0.631^{*}$ \\
Steals $(n)$ & 0.133 & 0.377 & 0.005 & 0.387 \\
Blocks $(n)$ & 0.451 & -0.228 & 0.241 & 0.016 \\
Points $(n)$ & 0.221 & 0.525 & 0.744 & 0.207 \\
General dispersion & 2.764 & 2.881 & 3.465 & 1.681 \\
\% dispersion & 0.173 & 0.181 & 0.217 & 0.106 \\
\hline
\end{tabular}

* trend towards statistically significant differences at a factor value between $>0.5$ and $<0.7$

Table 3. Grouping of competitive activity structure elements in highly skilled basketball players in the won games in accordance with the factor loading values, $n=7936$

\begin{tabular}{|c|c|c|c|c|}
\hline \multirow{2}{*}{$\begin{array}{l}\text { Indicators } \\
\text { of competitive activity }\end{array}$} & \multicolumn{4}{|c|}{ Values of factor loading } \\
\hline & Group 1 of factors & Group 2 of factors & Group 3 of factors & Group 4 of factors \\
\hline Time (min) & 0.447 & $0.595^{*}$ & 0.356 & 0.332 \\
\hline 2-point shots $(n)$ & 0.404 & 0.067 & $0.624^{*}$ & 0.407 \\
\hline 2-point shots (\%) & 0.455 & 0.087 & $0.610^{*}$ & 0.398 \\
\hline 3-point shots $(n)$ & 0.014 & 0.866 & 0.145 & -0.061 \\
\hline 3-point shots (\%) & 0.060 & 0.893 & 0.187 & 0.021 \\
\hline Free throws $(n)$ & 0.082 & 0.169 & 0.914 & -0.0194 \\
\hline Free throws (\%) & 0.166 & 0.138 & 0.907 & -0.004 \\
\hline Offensive rebound $(n)$ & 0.718 & -0.223 & 0.109 & 0.101 \\
\hline Defensive rebound $(n)$ & 0.770 & 0.269 & 0.218 & 0.047 \\
\hline Total rebounds $(n)$ & 0.916 & 0.131 & 0.204 & 0.046 \\
\hline Assists $(n)$ & 0.0129 & $0.584^{*}$ & 0.195 & 0.305 \\
\hline Fouls $(n)$ & 0.131 & -0.046 & -0.088 & $0.682^{*}$ \\
\hline Turnovers $(n)$ & 0.009 & 0.174 & 0.303 & $0.658^{*}$ \\
\hline Steals $(n)$ & 0.111 & 0.404 & 0.078 & 0.277 \\
\hline Blocks $(n)$ & 0.463 & -0.218 & 0.265 & -0.089 \\
\hline Points $(n)$ & 0.257 & 0.538 & 0.717 & 0.187 \\
\hline General dispersion & 2.862 & 2.969 & 3.426 & 1.561 \\
\hline$\%$ dispersion & 0.179 & 0.186 & 0.215 & 0.098 \\
\hline
\end{tabular}

\footnotetext{
* trend towards statistically significant differences at a factor value between $>0.5$ and $<0.7$
} 
Table 4. Grouping of competitive activity structure elements in highly skilled basketball players in the lost games in accordance with the factor loading values, $n=3088$

\begin{tabular}{lcccc}
\hline \multirow{2}{*}{$\begin{array}{l}\text { Indicators of competitive } \\
\text { activity }\end{array}$} & \multicolumn{4}{c}{ Values of factor loading } \\
\cline { 2 - 5 } & Group 1 of factors & Group 2 of factors & Group 3 of factors & Group 4 of factors \\
\hline Time (min) & 0.564 & 0.426 & 0.47 & 0.312 \\
2-point shots ( $($ ) & 0.491 & 0.402 & 0.014 & 0.548 \\
2-point shots (\%) & 0.491 & 0.458 & 0.4 & 0.510 \\
3-point shots (n) & 0.871 & -0.114 & 0.061 & 0.079 \\
3-point shots (\%) & 0.837 & -0.099 & 0.195 & 0.198 \\
Free throws ( $(n)$ & 0.133 & 0.134 & 0.089 & 0.927 \\
Free throws (\%) & 0.153 & 0.166 & 0.072 & 0.926 \\
Offensive rebound $(n)$ & -0.135 & 0.716 & -0.113 & 0.159 \\
Defensive rebound $(n)$ & 0.057 & $0.693^{*}$ & 0.321 & 0.331 \\
Total rebounds $(n)$ & -0.009 & 0.839 & 0.213 & 0.328 \\
Assists $(n)$ & 0.387 & 0.029 & 0.706 & 0.095 \\
Fouls $(n)$ & 0.168 & 0.302 & 0.276 & 0.002 \\
Turnovers $(n)$ & 0.482 & 0.267 & 0.409 & 0.021 \\
Steals $(n)$ & 0.046 & 0.076 & 0.762 & 0.108 \\
Blocks $(n)$ & 0.131 & $0.655^{*}$ & -0.265 & -0.026 \\
Points $(n)$ & 0.721 & 0.221 & 0.065 & 0.634 \\
General dispersion & 3.269 & 2.959 & 1.825 & 3.070 \\
$\%$ dispersion & 0.205 & 0.185 & 0.115 & 0.192 \\
\hline
\end{tabular}

* trend towards statistically significant differences at a factor value between $>0.5$ and $<0.7$

Table 5. Generalized data of grouping the competitive activity structure elements in qualified basketball players in accordance with the factor loading values, $n=11024$

\begin{tabular}{|c|c|c|c|c|}
\hline \multirow{2}{*}{$\begin{array}{l}\text { Grouping elements } \\
\text { of the competitive } \\
\text { activity structure }\end{array}$} & \multicolumn{4}{|c|}{ Factor group number } \\
\hline & 1 & 2 & 3 & 4 \\
\hline \multirow{14}{*}{ Won games } & - & Time & - & - \\
\hline & - & - & 2-point shots & - \\
\hline & - & - & $\%$ 2-point shots & - \\
\hline & - & 3-point shots & - & - \\
\hline & - & $\%$ 3-point shots & - & - \\
\hline & - & - & Free throws & - \\
\hline & - & - & \% Free throws & - \\
\hline & Offensive rebound & - & - & - \\
\hline & Defensive rebound & - & - & - \\
\hline & Rebounds & - & - & - \\
\hline & - & Assists* & - & - \\
\hline & - & - & - & Fouls* \\
\hline & - & - & - & Turnovers* \\
\hline & - & - & Points & - \\
\hline \multirow{11}{*}{ Lost games } & 3-point shots & - & - & - \\
\hline & $\%$ 3-point shots & - & - & - \\
\hline & - & - & - & Free throws \\
\hline & - & - & - & $\%$ Free throws \\
\hline & - & Offensive rebound & - & - \\
\hline & - & Defensive rebound ${ }^{*}$ & - & - \\
\hline & - & Turnovers & - & - \\
\hline & - & - & Assists & - \\
\hline & - & - & Steals & - \\
\hline & - & Blocks & - & - \\
\hline & Points & - & - & - \\
\hline
\end{tabular}

* trend towards statistically significant differences at a factor value between $>0.5$ and $<0.7$ 
E. Doroshenko et al., Competitive activity structure in basketball

won games; and offensive rebounds, the total number of rebounds, and blocks in the lost games.

The third group of factors includes quantitative and qualitative indicators of 2-point shots, free throws, and scored points in the won games; and quantitative indicators of assists and steals in the lost games.

The fourth group of factors involves only 2 indicators (quantitative and qualitative indicators of free throws, Table 4).

Consequently, the grouping of the competitive activity structure elements in qualified basketball players by the factor analysis methods allows us to determine the presence or absence of significant differences in the won and lost games (Table 5).

As a result of experimental studies, the newest data were obtained on the grouping of competitive activity elements of the technical and tactical indicators in highly qualified basketball players: participants of the final tournament of the European Basketball Championship 2017. The opinion of specialists was also confirmed [6,24] on the importance of studying the competitive activity indicators with factor analysis methods in won and lost games, as it allows to develop scientific and methodological actions for improving the educational and training process.

\section{Discussion}

According to the authors who studied the competitive activity structure of qualified basketball players using factor analysis [6, 8], these methods are quite effective. Problematic questions for the researchers are the rather high complexity of the selection of competitive activity indicators and the interpretation of the results obtained by using methods of factor analysis. The main difficulty in selecting elements of the competitive activity structure of qualified basketball players is that researchers need to select indicators that do not duplicate the factor loading of one another. In the competitive activity structure, as a rule, the indicators are analysed that are used in assessing the effectiveness of technical and tactical actions [18, 26], including free throws, 2-point shots, and 3-point shots. On the one hand, different types of shots in the process of studying the competitive activity structure in some way duplicate the corresponding factor values, on the other - these elements present significant differences, which is also significant [24] for adequate procedures of factor analysis. In our opinion, it is preferable to use some duplication of indicators of the competitive activity structure (analysis of the parameters of free throws, 2-point shots, and 3-point shots) in the factor analysis process, since the changes in the primary R matrix will not be significant.

Strong restrictions on the selection of indicators for studying the competitive activity structure of qualified basketball players with the help of factor analysis methods are necessary for optimal mathematical and statistical processing of the obtained results. Therefore, with regard to the logic of research in the field of Olympic and professional sports, the most important is the selection of elements that most fully characterize the competitive activity structure, even taking into account some duplication of indicators, e.g. free throws, 2-point shots, and 3-point shots.

In addition, the discussed issues include the problems of interpretation of indicators that are obtained as a result of applying a factor analysis variety - principal component analysis with Kaiser normalization and varimax orthogonal rotation of the primary $\mathrm{R}$ matrix. In particular, the indicator of played time is interpreted by researchers [26] as a value for calculating the individual (relative) competitive activity efficiency of qualified basketball players. In the study by Kyrychenko and Doroshenko [9], the value of the played time indicators is used as a separate component of the competitive activity structure, which indicates its efficiency or inefficiency. In our opinion, both methodical approaches can be applied in the process of competitive activity structure factor analysis of highly skilled basketball players with expert advice of highly qualified specialists for each specific case.

Also significant, in terms of scientific discussion, are the problems of forming a certain factor analysis algorithm for studying the competitive activity structure of qualified basketball players. In our opinion, this algorithm should contain the following components: selection of elements of the competitive activity structure on the basis of mathematical and statistical approaches; isolating the main components by using Kaiser normalization and varimax orthogonal rotation of the primary R matrix; interpretation of competitive activity structure indicators and development of methodological recommendations for improving the training process. Despite the existence of controversial positions, the factor analysis methods are adequate for studying the competitive activity structure.

\section{Conclusions}

1. The study of the competitive activity structure of qualified basketball players by using the factor analysis methods shows significant differences in the won and lost matches, with the 4 most significant in- 
dicators of factor loading and the correlating elements selection of $67.42 \%$ for the won games and $69.5 \%$ for the lost games, which allows to state a high degree of reliability of the obtained experimental results. Differences in the competitive activity structure of qualified basketball players in the won and lost matches were determined in 4 groups of factors. Differences in the overall competitive activity structure or the competitive activity structure of qualified basketball players in won games were not established.

2. Factor analysis is quite effective and informative for studying the competitive activity structure of qualified basketball players. In the process of investigating the competitive activity structure in basketball by using factor analysis, selection of indicators and expert interpretation of the results are most difficult.

3. Prospects for further research in this area are based on the refinement of the factor analysis algorithm of the competitive activity structure in qualified basketball players.

\section{Disclosure statement}

No author has any financial interest or received any financial benefit from this research.

\section{Conflict of interest}

The authors state no conflict of interest.

\section{References}

1. Iberla K. Factor analysis. Moscow: Statistics; 1980.

2. Vlachopoulos SP, Karageorghis CI, Terry PC. Hierarchical confirmatory factor analysis of the Flow State Scale in exercise. J Sports Sci. 2000;18(10):815-823; doi: 10.1080/026404100419874.

3. Kawabata M, Mallett CJ. Interpreting the Dispositional Flow Scale-2 scores: a pilot study of latent class factor analysis. J Sports Sci. 2012;30(11):1183-1188; doi: 10.1080/02640414.2012.695083.

4. Li Y, Wang X, Chen X, Dai B. Exploratory factor analysis of the functional movement screen in elite athletes. J Sports Sci. 2015;33(11):1166-1172; doi: 10.1080/ 02640414.2014 .986505$.

5. Kozina ZL. Factor models of physical preparedness of high-level volleyball players of different game roles [in Ukrainian]. Pedagog Psychol Med Biol Probl Phys Train Sports. 2007;9:80-85.

6. Kozina ZL, Voskoboinik A, Grin L, Gorilchanik O. Application of multidimensional and nonlinear regression analysis methods for revealing regularities of individual dynamics of competitive performance in basketball [in Russian]. Health Sport Rehab. 2015; 1:12-14.

7. Okazaki VHA, Rodacki ALF. Basketball jump shot performed by adults and children. Hum Mov. 2018;19(1): 71-79; doi: 10.5114/hm.2018.73615.
8. Kabaciński J, Murawa M, Fryzowicz A, Dworak LB. A comparison of isokinetic knee strength and power output ratios between female basketball and volleyball players. Hum Mov. 2017;18(3):40-45; doi: 10.1515/ humo-2017-0022.

9. Kyrychenko R, Doroshenko E. Study of the structure of technical and tactical activity of skilled basketball players by the method of main components [in Ukrainian]. Pedagog Psychol Med Biol Probl Phys Train Sports. 2006;5:36-41.

10. Calvo JL, García AM, Navandar A. Analysis of mismatch after ball screens in Spanish professional basketball. Int J Perform Anal Sport. 2017;17(4):555-562; doi: 10.1080/24748668.2017.1367999.

11. Gryko K, Mikołajec K, Maszczyk A, Cao R, Adamczyk JG. Structural analysis of shooting performance in elite basketball players during FIBA EuroBasket 2015. Int J Perform Anal Sport. 2017;18(2):380-392; doi: 10.1080/24748668.2018.1479923.

12. Teck KK, Wang CKJ, Mallett CJ. Discriminating factors between successful and unsuccessful elite youth Olympic female basketball teams. Int J Perform Anal Sport. 2012;12(1):119-131; doi: 10.1080/24748668. 2012.11868588.

13. Bazanov B, Võhandu P, Haljand R. Factors influencing the teamwork intensity in basketball. Int J Perform Anal Sport. 2006;6(2):88-96; doi: 10.1080/24748668. 2006.11868375 .

14. Kozina Z, Jagiello W, Jagiello M. Determination of sportsmen's individual characteristics with the help of mathematical simulation and methods of multi-dimensional analysis. Pedagog Psychol Med Biol Probl Phys Train Sports. 2015;12:41-50; doi: 10.15561/ 18189172.2015.1207.

15. Villa G, Lozano S. Dynamic Network DEA approach to basketball games efficiency. J Oper Res Soc. 2018; 69(11):1738-1750; doi:10.1080/01605682.2017.1409158.

16. Gruber JJ, Gray GR. Factor patterns of variables influencing cohesiveness at various levels of basketball competition. Res Q Exerc Sport. 1981;52(1):19-30; doi: 10.1080/02701367.1981.10609291.

17. Hopkins DR. Factor analysis of selected basketball skill tests. Res Q. 1977;48(3):535-540; doi: 10.1080/ 10671315.1977.10615459.

18. Koryahin V, Dutchak M, Iedynak G, Blavt O, Galamandjuk L, Cherepovska E. The technical and physical preparation of basketball players. Hum Mov. 2018; 19(4):29-34; doi: 10.5114/hm.2018.77321.

19. Karpowicz K, Karpowicz M. Reflections on the changes observed in the structure of motor skills in young athletes. Hum Mov. 2013;14(3):221-228; doi: 10.2478/ humo-2013-0027.

20. Sampaio J, Janeira M, Ibáñez S, Lorenzo A. Discriminant analysis of game-related statistics between basketball guards, forwards and centres in three professional leagues. Eur J Sport Sci. 2006;6(3):173-178; doi: 10.1080/17461390600676200. 


\section{HUMAN MOVEMENT}

E. Doroshenko et al., Competitive activity structure in basketball

21. Sporiš G, Šango J, Vučetić V, Mašina T. The latent structure of standard game efficiency indicators in basketball. Int J Perform Anal Sport. 2006;6(1):120-129; doi: 10.1080/24748668.2006.11868360.

22. Scanlan A, Dascombe B, Reaburn P. A comparison of the activity demands of elite and sub-elite Australian men's basketball competition. J Sports Sci. 2011;29(11): 1153-1160; doi: 10.1080/02640414.2011.582509.

23. Ferreira AP, Volossovitch A, Sampaio J. Towards the game critical moments in basketball: a grounded theory approach. Int J Perform Anal Sport. 2014;14(2):428442; doi: 10.1080/24748668.2014.11868732.

24. Okazaki VHA, Rodacki ALF, Satern MN. A review on the basketballjump shot. Sports Biomech. 2015;14(2):190205; doi: 10.1080/14763141.2015.1052541.

25. Liba MR. Factor analysis of strength variables. Res Q. 1967;38(4):649-662; doi: 10.1080/10671188.1967. 10616509.

26. Kozina Z, Repko O, Ionova O, Boychuk Y, Korobeinik V. Mathematical basis for the integral development of strength, speed and endurance in sports with complex manifestation of physical qualities. J Phys Educ Sport. 2016;16(1):70-76; doi: 10.7752/jpes.2016.01012. 